\title{
Goldenhar's syndrome
}

\section{Oculoauriculo-vertebral dysplasia}

\author{
D. H. MELLOR, JOYCE E. RICHARDSON, and D. M. DOUGLAS \\ From the Department of Child Health, University of Aberdeen; Aberdeen Maternity Hospital; and The Royal Hospital \\ for Sick Children, Edinburgh
}

\begin{abstract}
Mellor, D. H., Richardson, J. E., and Douglas, D. M. (1973). Archives of Disease in Childhood, 48, 537. Goldenhar's syndrome: oculoauriculo-vertebral dysplasia. Three cases of Goldenhar's syndrome diagnosed over a 4-year period in the newborn nursery all showed epibulbar dermoids, auricular appendices, and vertebral anomalies which are considered to be the hallmarks of the syndrome. The infants were small-for-dates and showed feeding difficulties, which may be features of the condition. A variety of other malformations was present. The aetiology of the syndrome remains obscure. The importance of differentiating Goldenhar's syndrome from mandibulofacial dysostosis, hemifacial microsomia, and the various first arch syndromes is stressed.
\end{abstract}

Oculoauriculo-vertebral dysplasia was probably first described in 1845 by von Arlt, but went largely unnoticed until 1952 when Goldenhar recorded 3 new cases in addition to the 16 previously recorded. In 1963 Gorlin et al. reviewed the 40 cases reported up to that time. Subsequently, there have been sporadic reports of further cases (Smithells, 1964; Sugar, 1966; Darling, Feingold, and Berkman 1968; Dumars and Charles, 1968; Nessim-Morcos, Mathalone, and Kessel, 1968; Sen, Mohan, and Gupta, 1969; Krause, 1970; Kirkham, 1970; Bowen, Collum, and Rees, 1971 ; Rees, Collum, and Bowen, 1972). The syndrome is very easily recognized in the neonatal period, but when the condition is not known, a misdiagnosis of mandibulofacial dysostosis or unspecified first arch syndrome is usually made. We consider that accurate diagnosis is important for the correct management of children with Goldenhar's syndrome. We have seen 3 cases over a period of 4 years, and believe that the condition may be commoner than is generally considered.

\section{Case reports}

Case 1. A boy was born in 1968 after a pregnancy complicated by mild essential hypertension. Birthweight was $2600 \mathrm{~g}$ at 39 weeks' gestation. His parents were both 32 years of age. A sister born in 1963 has juvenile rheumatoid arthritis. Certain abnormalities were noted at the time of birth. There was a

Received 27 October 1972. colobomatous notch in both upper eyelids at the junction of inner third and outer two thirds (Fig. 1). Fleshy dermoid tumours filled the lower outer quadrant of each eye, encroaching on the corneal edges. The eyes had a slight antimongoloid slant. A polyp protruded from an enlarged left nostril and bilateral preauricular appendices were present. Skull $x$-rays showed calcification in the upper part of the falx cerebri. The cochleae and mastoid air cells could be discerned. $X$-rays of cervical and dorsal spine showed a sagittal cleft of the 5th dorsal vertebral body. Chromosome studies revealed a normal male karyotype $(46, \mathrm{XY})$. The nasal polyp was removed and histologically was found to be covered by epidermis with adipose and fibroconnective tissue composing the stalk.

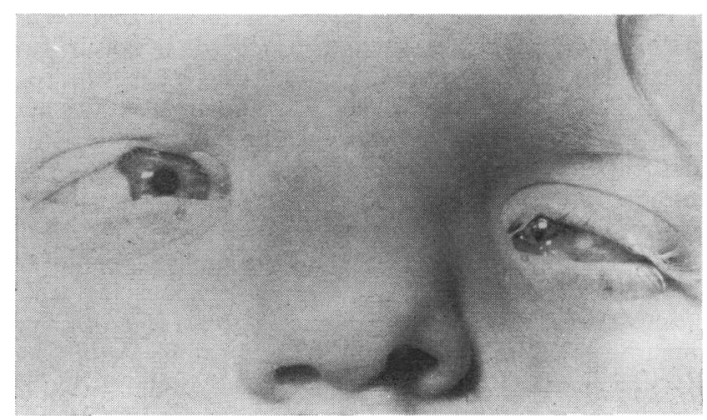

Fig. 1.-Case 1 at 3 months of age. His eyes have a slight antimongoloid slant and there are bilateral epibulbar lipodermoids and upper eyelid colobomata. 
At 11 months of age he was admitted to hospital for removal of the dermoid tumour from the left eye. It was adherent to the conjunctiva and cornea but was separated and excised as far back as possible into the orbit. Unfortunately, a progressive convergent squint developed over the next few months. At a second operation at 21 months of age a large amount of scar tissue was found contracting and pulling the left eye inwards. This was dissected out as much as possible and the left eye was moving freely at the end of the operation. Despite an apparently favourable immediate result, the squint had reappeared 3 weeks after operation, and at 27 months of age fibrous tissue was seen encroaching on the cornea of the left eye. At age 33 months the right-sided dermoid was excised and replaced by a $8 \mathrm{~mm}$ corneal-scleral lamellar graft (Mr. T. A. Casey, Queen Victoria Hospital, East Grinstead). The tumour was found to extend very far back and dissection was carried out to the level of the posterior pole. The eyelid colobomata were repaired at this time as it had been noted that because of them the corneas were exposed during sleep.

His hearing has been tested on several occasions and at no time has there been any question of impairment. Developmental progress has been satisfactory.

Case 2. A girl was born in 1969 after a normal pregnancy. Birthweight was $3600 \mathrm{~g}$ at a gestation of 41 weeks. Her 29-year-old mother was in good health and there was no parental consanguinity. 4 older sibs were all normal and thriving. After a spontaneous vertex delivery there was difficulty in establishing respiration, and the Apgar score was only 3 at 1 minute. Intubation was attempted, but this was unsuccessful because of an abnormal laryngeal structure. A tracheostomy at the age of 10 minutes was followed by rapid improvement. Many abnormalities were present. There was a marked right-sided facial hypoplasia involving maxilla and mandible with an associated torticollis. A coloboma involved the left upper eyelid and a lipodermoid encroached onto the cornea on the right side. The right ear was malformed and hypoplastic with complete atresia of the external auditory meatus. The left ear appeared normal apart from a preauricular appendix. The right half of the tongue was absent and there was a cleft of the soft palate. A cardiac murmur was considered to be significant and due probably to a persistent ductus arteriosus. At subsequent laryngoscopy the epiglottis and laryngeal inlet were very small and difficult to expose being situated high up under the tongue and deviated to the left. A normal female karyotype $(46, \mathrm{XX})$ was shown. Skull $x$-rays revealed a large parietal bony defect and a smaller one in the frontal region (Fig. 2). $X$-rays of the cervical spine showed multiple hemivertebrae. Bottle feeding was unsuccessful and the child had to be tube fed. Recurrent chest infections occurred which responded poorly to antibiotics and she eventually died at 5 weeks. Permission for necropsy was not obtained.

Case 3. In 1972 a boy weighing $2280 \mathrm{~g}$ at 38 weeks' gestation was born to healthy parents, aged 30 and 31 years. The membranes had been ruptured for 55 days but the pregnancy was otherwise uncomplicated. It was noted at delivery that the baby was abnormal. The face was asymmetrical due to left-sided facial hypoplasia and absence of the ramus and condyle of the left mandible (Fig. 3a). There was micrognathia, macrostomia, a high palatal vault, and a short lower labial frenum with a degree of bifid tongue. The combination of a receding chin and malar hypoplasia gave a parrot-like visage (Fig. 3b). Bilateral lipodermoids in the lower outer quadrants

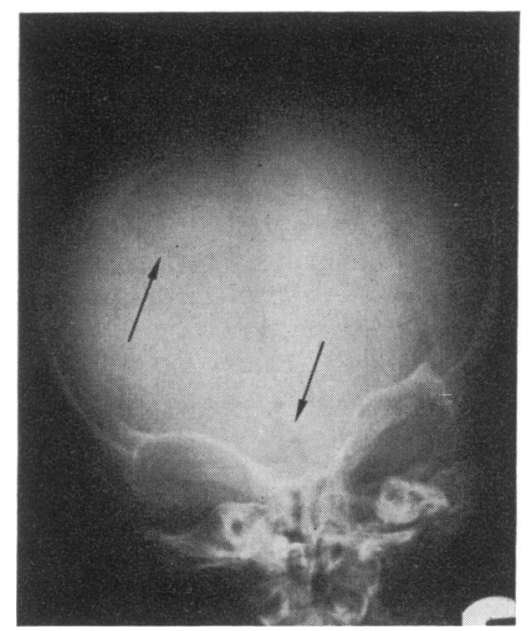

FIG. 2.-Skull x-ray of Case 2 showing the parietal and frontal bony defects (arrowed).

of both eyes did not involve the cornea. A pedunculated dermoid arose from the left epibulbar lipodermoid. The ears were well formed but the pinnae were rotated anteriorly and each led into a pinhole meatus. Preauricular appendices were present. The right thumb was hypoplastic and functionless.

$X$-rays confirmed the absence of the ramus and condyle of the left mandible. Tomograms showed asymmetry of the internal auditory meati and apparent dilatation of the semicircular canal systems. Middle ear cavities were not visualized. Modioli were identified, suggesting that cochleae were present. $X$-rays of the spine showed a sagittal cleft of the sixth dorsal vertebral body, 13 dorsal vertebrae, 13 pairs of ribs, and 6 lumbar vertebrae, the fifth lumbar being a hemivertebra. The right hand showed a very small first metacarpal bone and small proximal and terminal phalanges of the thumb. Complement fixation tests for a wide range of viruses and serum immunoglobulins were normal.

Feeding difficulties and a respiratory infection resulted in repeated hospitalization in the first 4 months. In spite of this his developmental progress has been satisfactory, and at 6 months of age he has shown some auditory responses to loud noises. 


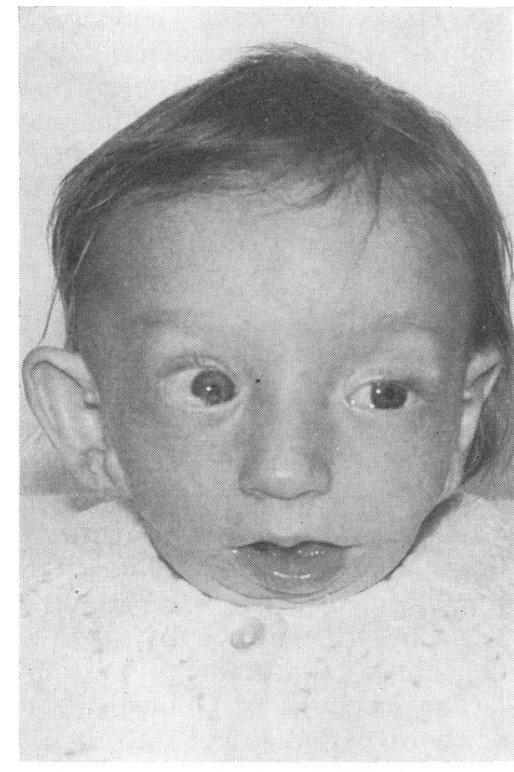

(a)

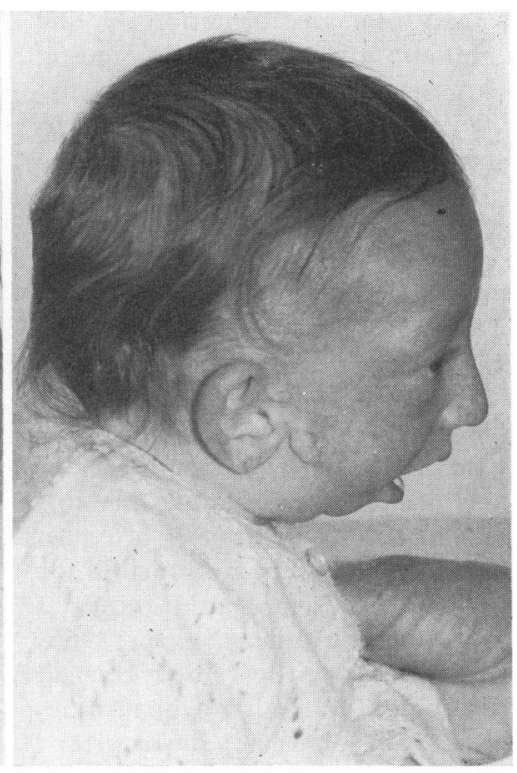

(b)

Fig. 3.-Case 3 at 6 months of age. (a) The left side of his face is hypoplastic and there are preauricular appendices and epibulbar lipodermoids. (b) The combination of malar hypoplasia and micrognathia gives his profile a characteristic appearance.

\section{Discussion}

These 3 cases have in common epibulbar dermoids, auricular appendices, and vertebral anomalies which are the hallmarks of Goldenhar's syndrome (Gorlin and Pindborg, 1964). In addition, each case shows other abnormalities which serve to emphasize the wide variety of malformations occurring in this syndrome (Table).

Pregnancy and delivery were uncomplicated in all
3 cases, but Cases 1 and 3 were below the fifth centile in weight for gestation (Thomson, Billewicz, and Hytten, 1968). Very few published reports of Goldenhar's syndrome give information on birthweight and gestation, but Smithells' (1964) case was also small-for-dates, suggesting that intrauterine growth retardation may be a feature of the condition. In the neonatal period 2 of the infants had severe feeding difficulties and required tube feeding. Both

TABLE

Comparison of features in 3 cases

\begin{tabular}{|c|c|c|c|}
\hline & Case 1 & Case 2 & Case 3 \\
\hline $\begin{array}{l}\text { Upper eyelid coloboma } \\
\text { Epibulbar dermoids } \\
\text { Antimongoloid slant } \\
\text { Preauricular appendices } \\
\text { External auditory meatal stenosis } \\
\text { Middle and inner ear malformations } \\
\text { Vertebral anomalies } \\
\text { Maxillary hypoplasia } \\
\text { Unilateral facial hypoplasia } \\
\text { Aplasia of mandibular ramus and condyle } \\
\text { Macrostomia } \\
\text { Laryngeal abnormalities } \\
\text { Cardiac defect } \\
\text { Cranial anomalies } \\
\text { Small-for-dates } \\
\text { Feeding difficulties }\end{array}$ & $\begin{array}{l}+ \\
+ \\
+ \\
+ \\
- \\
+ \\
- \\
- \\
- \\
- \\
+ \\
+ \\
-\end{array}$ & $\begin{array}{l}+ \\
+ \\
- \\
+ \\
+ \\
? \\
+ \\
+ \\
+ \\
+ \\
+ \\
+ \\
+ \\
+ \\
+\end{array}$ & $\begin{array}{l}\overline{+} \\
- \\
+ \\
+ \\
+ \\
+ \\
+ \\
+ \\
+ \\
+ \\
+ \\
+ \\
+\end{array}$ \\
\hline
\end{tabular}


of these children had oral malformations. The child who had no oral abnormalities had no feeding problem. It appears that feeding difficulties in the newborn with Goldenhar's syndrome are related to the severity of any oral malformations present.

The epibulbar dermoids are one of the most worrying features of the syndrome in that they may encroach onto the cornea and extend deeply into the orbit making surgical excision difficult. Removal of the left dermoid in Case 1 resulted in progressive fibrosis which extended onto the cornea and also caused an internal strabismus. The utilization of a corneal-scleral lamellar graft after the removal of the right dermoid may be the explanation for the lack of similar complications on that side. Colobomata of the upper eyelids are said to occur in $60 \%$ of cases, and it is interesting that these were responsible for imperfect corneal cover in Case 1 and required repair to avoid exposure keratitis. Sugar (1966) and Bowen et al. (1971) have described corneal anaesthesia accompanying Goldenhar's syndrome, which may be responsible in some cases for recurrent keratitis and scarring.

Our 3 cases show the range of ear abnormality to be seen in this condition: from preauricular appendices alone to any combination of abnormalities of the external, middle, and inner ear. All children with Goldenhar's syndrome should be considered to be 'at risk' for hearing impairment and kept under regular surveillance until they can be shown to have nomal hearing.

A wide variety of skeletal abnormalities occurred in our cases. All showed some vertebral anomaly of a severity varying from an occult cleft of a single vertebral body to multiple hemivertebrae producing clinical deformity. In addition, Case 1 had some calcification of the falx cerebri, Case 2 showed parietal and frontal bony defects in the skull, and Case 3 had hypoplasia of a first metacarpal and aplasia of the left ramus of the mandible. We agree with Gorlin and Pindborg (1964) that bony anomalies are probably more frequent than previously reported in this condition.

Embryologically the syndrome is thought to arise by some abnormal process affecting the mesoblast which induces the branchial and vertebral systems (Gorlin and Pindborg, 1964). The primary cause of this faulty embryological development is unknown. No evidence of any hereditary pattern has been found in any of the reported cases with the exception of Krause (1970) who described the syndrome affecting a brother and sister. However, some doubt must exist about the diagnosis in the sister who had a left-sided conjunctival lipoma but no other features of Goldenhar's syndrome. The sporadic occurrence of Goldenhar's syndrome is in contrast to mandibulofacial dysostosis and the various first arch syndromes, most of which are inherited as autosomal dominants of varying expressivity (McKenzie, 1966). Chromosome studies have now been reported in a few cases of Goldenhar's syndrome and, like ours, have always been normal. It appears, therefore, that the syndrome is neither inherited nor associated with any chromosomal abnormality. Jongbloet (1971) has suggested that Goldenhar's syndrome may result from fertilization of an overripe ovum. He quotes the work of Witschi (1952) which showed the teratogenic effect of ageing on frogs' eggs before fertilization. 'Overripeness ovopathy' seems to be a difficult hypothesis to prove as the cause of any human malformation. The fact that the parents of Jongbloet's case practised periodic abstinence seems inconclusive evidence of such an aetiology for Goldenhar's syndrome.

The diagnosis of Goldenhar's syndrome in the newborn period is not difficult. Nearly all cases will show the triad of epibulbar dermoids, auricular appendices, and vertebral anomalies. Various other abnormalities are common but much less constant. The differential diagnosis includes mandibulofacial dysostosis, hemifacial microsomia, and the various first arch syndromes. Epibulbar dermoids, vertebral anomalies, and upper lid colobomata do not occur in either mandibulofacial dysostosis or hemifacial microsomia, and provide useful identifying features. The importance of correct diagnosis lies with possible genetic counselling and with the prognosis for future intellectual ability. Goldenhar's syndrome is sporadic and so most unlikely to affect any subsequent children in the family. In contrast, mandibulofacial dysostosis is inherited as an autosomal dominant of varying expressivity (Smith, 1970), and future pregnancies would be at risk if either parent showed any evidence of the disorder. The prognosis for future intellectual capacity is good in Goldenhar's syndrome as mental retardation occurs in only $10 \%$ of cases (Gorlin and Pindborg, 1964) and then is usually of mild degree.

\section{REFERENCES}

Arlt, C. F. von (1845). Klinische Darstellung der Krankheiten des Auges, Vol. 3, p. 376. Braumüller, Vienna.

Bowen, D. I., Collum, L. M. T., and Rees, D. O. (1971). Clinical aspects of oculo-auriculo-vertebral dysplasia. British fournal of Ophthalmology, 55, 145.

Darling, D. B., Feingold, M., and Berkman, M. (1968). The roentgenological aspects of Goldenhar's syndrome (oculoauriculovertebral dysplasia). Radiology, 91, 254.

Dumars, K., Jr., and Charles, M. A. (1968). Oculo-auriculovertebral dysplasia; Goldenhar's syndrome. Rocky Mountain Medical fournal, 65, 44. 
Goldenhar, M. (1952). Associations malformatives de l'oeil et de l'oreille. fournal de Génétique Humaine, 1, 243.

Gorlin, R. J., Jue, K. L., Jacobsen, U., and Goldschmidt, E. (1963). Oculoauriculovertebral dysplasia. Fournal of Pediatrics, 63, 991.

Gorlin, R. J., and Pindborg, J. J. (1964). Syndromes of the Head and Neck. McGraw-Hill, New York.

Jongbloet, P. H. (1971). Mental and Physical Handicaps in Connection with Overripeness Ovopathy. H. E. Stenfert Kroese n. v., Leiden.

Kirkham, T. H. (1970). Goldenhar's syndrome with inner ear defects. Fournal of Laryngology and Otology, 84, 855.

Krause, U. (1970). The syndrome of Goldenhar affecting two siblings. Acta Ophthalmologica, 48, 494.

McKenzie, J. (1966). The first arch syndrome. Developmental Medicine and Child Neurology, 8, 55.

Nessim-Morcos, I., Mathalone, M. B. R., and Kessel, I. (1968). Goldenhar's syndrome. British Medical fournal, 1, 489.

Rees, D. O., Collum, L. M. T., and Bowen, D. I. (1972). Radiological aspects of oculo-auriculo-vertebral dysplasia. British fournal of Radiology, 45, 15.
Sen, D. K., Mohan, H., and Gupta, D. K. (1969). The syndrome of Goldenhar. Acta Ophthalmologica, 47, 1044.

Smith, D. W. (1970). Recognizable Patterns of Human Malformation. Saunders, Philadelphia.

Smithells, R. W. (1964). Oculo-auriculo-vertebral syndrome (Goldenhar's syndrome). Developmental Medicine and Child Neurology, 6, 406.

Sugar, H. S. (1966). Oculoauriculovertebral dysplasia: syndrome of Goldenhar. American fournal of Ophthalmology, 62, 678.

Thomson, A. M., Billewicz, W. Z., and Hytten, F. E. (1968). The assessment of fetal growth. Fournal of Obstetrics and Gynaecology of the British Commonwealth, 75, 903.

Witschi, E. (1952). Overripeness of the egg as a cause of twinning and teratogenesis. Cancer Research, 12, 763.

Correspondence to Dr. D. H. Mellor, University of Aberdeen Department of Child Health, Foresterhill, Aberdeen AB9 2ZD. 